\title{
DIVERSIDADE DE GÊNERO E SEXUALIDADE NO PROCESSO FORMATIVO DOCENTE
}

\author{
GENDER DIVERSITY AND SEXUALITY IN THE TEACHING \\ FORMATIVE PROCESS
}

\author{
Clarinês Hames (clarines.hames@iffarroupilha.edu.br) \\ Instituto Federal Farroupilha (IFFAR), Campus Santo Augusto \\ Adriana Toso Kemp (adriana.kemp@iffarroupilha.edu.br) \\ Instituto Federal Farroupilha (IFFAR), Campus Santo Ângelo
}

\begin{abstract}
Resumo:
O foco deste texto é refletir sobre questões de sexualidade e diversidade de gênero a partir de interações realizadas na formação inicial de professores de Ciências/Biologia. Foi desenvolvida uma sequência didática nas aulas de Prática de Ensino de Biologia II, em três momentos: aulas, interações nas escolas e elaboração de artigo. Ao final, os acadêmicos responderam à questão: "no seu entendimento, a área de Biologia/Ciências tem responsabilidade na discussão das questões de gênero e sexualidade? Justifique." Percebeu-se que as concepções dos acadêmicos ainda têm um enfoque na anatomia e fisiologia de sistemas, doenças e prevenção. A dimensão afetiva e prazerosa da sexualidade é negligenciada. As reflexões apontam para a ampliação do papel da Ciência/Biologia nessas discussões, bem como a importância de um diálogo qualificado com outras áreas do conhecimento.
\end{abstract}

Palavras-chave: diversidade sexual e de gênero; ensino de ciências; formação de professores(as).

\begin{abstract}
:
The focus of this text is to reflect on issues of sexuality and gender diversity from interactions carried out in the initial formation of Science/Biology teachers. A didactic sequence was developed in the classes of Biology Teaching Practice II, in three moments: classes, interactions in schools and article writing. In the end, the academics answered the question: "in your understanding, is the Biology/Science area responsible for discussing gender and sexuality issues? Justify." It was noticed that the conceptions of the academics still have a focus on the anatomy and physiology of systems, diseases and prevention. The affective and pleasurable dimension of sexuality is neglected. The reflections point to the expansion of the role of Science/Biology in these discussions, as well as the importance of a qualified dialogue with other areas of knowledge.
\end{abstract}

Key words: sexual diversity, science teaching; teacher training. 


\section{INTRODUÇÃO}

Esta reflexão foi desenvolvida a partir de interações em aulas na disciplina de Prática de Ensino de Biologia II, no segundo semestre do curso de Licenciatura em Ciências Biológicas do Instituto Federal Farroupilha, Campus Santo Augusto. A ementa da referida disciplina propõe uma discussão sobre a sexualidade no âmbito escolar, levando-se em conta aspectos biológicos, emocionais e psicológicos (BRASIL, 2015).

Para além do que prevê a ementa, os acadêmicos interagiram e dialogaram com professores e estudantes em escolas de educação básica, com o objetivo de observar se questões de gênero e diversidade sexual são discutidas na escola e de que modo. Depois, elaboraram um artigo, o que exigiu aprofundamento teórico.

As reflexões tecidas aqui se estruturam a partir das respostas construídas por esses acadêmicos a um questionamento sobre a responsabilidade da área de Ciências/Biologia nas discussões referentes a gênero e sexualidade na escola. A pergunta foi respondida por escrito pelos licenciandos, que são aqui identificados pela letra $\mathrm{A}$ e sequência numérica, para preservar seu anonimato.

A discussão qualificada dessa temática, ao longo de toda a escolaridade dos sujeitos é de grande importância para sua formação, concebida como um processo alargado, que vai além do aspecto racional. Não se pode pensar uma formação para a cidadania, nos moldes em que prevê a legislação educacional brasileira, desconsiderando a abordagem das questões de gênero e diversidade sexual.

O Brasil, segundo a ONU (2019), é um dos países que mais registra agressões contra LGBTI (Lésbicas, Gays, Bissexuais, Travestis e Intersexuais). "Segundo dados do Grupo Gay da Bahia, em 2018 houve 520 crimes contra pessoas LGBTI" (ONU 2019). Acreditamos que as discussões sobre diversidade de gênero ainda sejam muito incipientes nas escolas e, quando ocorrem, ainda ficam limitadas ao enfoque biológico. Fica evidente, portanto, a necessidade de se abordar essa temática no contexto escolar, de modo planejado e com o devido embasamento teórico-conceitual.

Assim, o objetivo deste texto é refletir sobre questões de sexualidade e diversidade de gênero no processo formativo docente a partir de interações realizadas na 
formação inicial de professores de Ciências/Biologia, de modo a alargar o horizonte de compreensão do papel dessa área de conhecimento nessas discussões.

\section{DESENVOLVIMENTO}

A escola é o local onde o sujeito tem acesso ao conhecimento historicamente construído pela humanidade nas mais diversas áreas. Todavia, é, também, "no tocante à sexualidade, um local de ocultamento (LOURO, 2001, p. 30). A autora ressalta que na escola é muito difícil para as pessoas assumirem sua condição não heterossexual. Nesse sentido, "o lugar do conhecimento mantém-se, com relação à sexualidade, como o lugar do desconhecimento e da ignorância" (LOURO, 2001, p. 30). Se a escola se abstém de fazer essa discussão, a formação dos sujeitos fica comprometida, uma vez que nos demais espaços formativos esses assuntos quase sempre são encarados como tabus, carregados de preconceitos e moralismos.

Seffner e Silva ressaltam que "educar para os lugares de gênero e sexualidade é uma das funções tradicionais da escola" (2013a, p. 67). Assim também A10 entende que "a escola é um espaço onde o debate deve acontecer, pois é necessário possibilitar ao aluno o desenvolvimento do pensamento crítico, permitindo um olhar mais reflexivo sobre as questões de gênero e sexualidade, resultando em um convívio mais respeitoso" ". Isso aponta para a necessidade de assegurar espaço-tempo no currículo escolar para a discussão dessa temática. Entretanto, somente isso não garante uma abordagem adequada da temática, ou seja, uma discussão capaz de questionar a heteronormatividade e romper com determinados discursos machistas, sexistas, preconceituosos e discriminatórios. É imprescindível trazer para o currículo debates sobre a diversidade de identidades de gênero e orientação sexual, uma vez que, reiteradamente, a abordagem acerca de gênero e sexualidade na escola se restringe à reprodução da espécie e aos cuidados com o corpo no que tange às infecções sexualmente transmissíveis (IST) e à gravidez na adolescência (SEFFNER; SILVA, 2013).

${ }^{1}$ Os trechos transcritos das respostas dos acadêmicos à questão de pesquisa aparecem ao longo deste texto destacados em itálico, de modo a diferenciar das citações de autores de referência. 
Compreendemos sexualidade "como uma descrição geral para a série de crenças, comportamentos, relações e identidades socialmente construídas e historicamente modeladas" (WEEKS, 2001, p. 43). Além disso, concordamos com Louro de que a sexualidade, "envolve rituais, linguagens, fantasias, representações, símbolos, convenções... processos profundamente plurais e culturais” (2001, p. 11). Gênero pode ser definido, segundo Seffner e Silva com apoio em Joan Scott, como "um elemento constitutivo das relações sociais baseadas nas diferenças percebidas entre os sexos, assim como é uma forma primária de dar significado às relações de poder" (2013a, p. 66).

A visão de A5, entretanto, corrobora o entendimento reducionista do papel da área de Ciências/Biologia nas discussões de gênero e sexualidade. Em seu entendimento, "é competência da disciplina trazer assuntos como doenças sexualmente transmissíveis e reprodução humana [...] encaixaria trazer exercícios sobre os assuntos de gênero e sexualidade". Para além de reduzir a discussão de gênero e sexualidade a aspectos anatômicos e físiológicos, A5 traz a inclusão dessas temáticas ao modo de um "encaixe", denotando a pouca importância atribuída à temática no planejamento do ensino.

Ao lidar com questões de gênero, sexualidade e diversidade na escola, os professores, muitas vezes, fazem uma abordagem moralizante, trazendo suas experiências e opiniões pessoais, sem aporte teórico-conceitual. Além disso, "há um silêncio sobre a dimensão afetiva e prazerosa da sexualidade, o que parece distanciar o discurso dos professores do universo adolescente" (MADUREIRA, 2007, p. 10).

Chama a atenção o fato de que, dos 18 acadêmicos que responderam à questão de pesquisa, nenhum mencionou a dimensão afetiva e prazerosa da sexualidade. Mesmo tendo vivenciado a disciplina, ido à escola e elaborado um artigo, o que exigiu um arcabouço de leituras, a maioria dos acadêmicos mantém a concepção de que o ensino de Ciências/Biologia tem como função significar conceitos de anatomia e fisiologia dos sistemas reprodutores, IST, dentre outros.

As respostas, na sua grande maioria, giram em torno do aspecto biológico em sua dimensão anatômica e físiológica. Para A2, "a biologia é a melhor matéria escolar para discutir sobre esse tema, já que ela explica a vida". A5 afirma que "só a biologia pode 
explicar assuntos como esses de gênero e sexualidade". No entendimento de Silva, "essa ideia é parte de um discurso que opera com a noção de que a dimensão biológica exclui a presença da abordagem da sexualidade no espaço escolar, se tomamos a noção de sexualidade para além desta dimensão" (2015, p. 4).

Nesse sentido, contudo, há que se reconhecer o impacto positivo da universalização do ensino fundamental para a ampliação do leque de identidades culturais, levando "a escola a acolher muitos sujeitos que estavam alijados do acesso e da permanência nela. [...] Todos têm direito à educação, mas todos devem aprender a conviver e se respeitar no espaço público escolar” (SEFFNER, 2011, p.570).

No bojo desse entendimento, merecem destaque as observações de alguns acadêmicos quanto ao alargamento da compreensão do papel da biologia nas discussões sobre gênero e diversidade. A10 assim se expressa: "a disciplina de ciências/biologia tem responsabilidade nessas discussões, já que estudamos a vida e toda sua diversidade, assim precisamos criar debates, fazer leituras de diferentes autores, bem como de livros didáticos e desenvolver trabalhos que envolvam essa temática". Isso aponta para a necessidade de os professores estudarem os pressupostos teóricos e metodológicos acerca desse conteúdo. Corrobora esse entendimento a afirmação de que

Ao dirigir o foco para o caráter 'fundamentalmente social', não há, contudo, a pretensão de negar que o gênero se constitui com ou sobre corpos sexuados, ou seja, não é negada a biologia, mas enfatizada, deliberadamente, a construção social e histórica produzida sobre as características biológicas (LOURO, 2014, p. 25-26).

Outro elemento que emerge das respostas dadas pelos acadêmicos diz respeito à ampliação do campo de debates sobre as questões de gênero e diversidade sexual. Sobre isso, A10 entende que "essa questão não deve ser apenas debatida na disciplina de ciências, mas outras também devem falar sobre o tema". A5 argumenta que "essas questões deveriam ser discutidas como um todo, a escola em si abordar isso com os alunos". Também A6 compreende que "são temas que não podem ser isolados dos diálogos escolares [...] não só a área de biologia/ciências, mas todas as outras áreas poderiam estar preparadas para poder ajudar na abordagem dos referidos assuntos". Ainda nesse sentido, também se expressa A1, afirmando que "todas as áreas têm a mesma responsabilidade na formação do ser humano". 
Nessa direção também argumenta Seffner: "saber ler, argumentar, escrever, selecionar ideias, compreender o ponto de vista do outro, implicam atitudes pessoais difíceis de obter" (2011, p. 570). Para isso, é imprescindível o trabalho de um professor, cuja formação inicial e continuada precisa ser atravessada pelos pressupostos teóricoconceituais acerca de gênero e diversidade sexual. Nessa mesma linha de compreensão, A10 observa que "é preciso investir na formação dos professores, pois a maioria ainda não sabe como falar sobre gênero e sexualidade dentro da escola".

Nesse sentido, cabe destacar ainda a relevância de políticas de equidade, a fim de promover um ambiente escolar mais sadio para todos os sujeitos envolvidos no processo de ensino e aprendizagem, "pois todos nós temos atributos pessoais que podem nos tornar alvo de estigma, gerando tensão social, que diminui as chances de rendimento escolar" (SEFFNER, 2011, p. 571).

\section{CONSIDERAÇÕES FINAIS}

As reflexões tecidas neste texto evidenciam a responsabilidade da área de Ciências/Biologia na ampliação e aprofundamento das discussões sobre gênero e diversidade sexual no contexto escolar. Entretanto, apontam, também, para a necessidade de que as demais áreas que integram o rol de disciplinas escolares abordem essas temáticas, pois essas questões vão além do aspecto biológico, uma vez que se inscrevem na cultura e são produtoras de subjetividades. Os debates sobre gênero "permitem-nos compreender sobre diferenças entre homens e mulheres produzidas no âmbito da cultura e da organização social. Diferenças que, assim como a sexualidade, ordenam, hierarquizam e instituem lugares na sociedade" (SEFFNER; SILVA, 2013b, p. 205).

Assim, fica claro que para abordar adequadamente essas temáticas no processo formativo escolar os professores precisam ter conhecimento teórico-conceitual. Entretanto, é imprescindível, também, que estejam sensibilizados para desenvolver um trabalho efetivamente formativo, não meramente informativo. Os professores "precisam ter conhecimento sobre o assunto e estar sensibilizados para realizar um diálogo de qualidade e que auxilie na construção de uma sociedade inclusiva e de respeito às diversidades" (LACORTE; HAMES, 2018, p. 206). 
Para "transformar a educação num processo mais prazeroso, mais efetivo e mais intenso" (LOURO, 2004, p. 72), a trajetória de formação de professores precisa ser atravessada pela compreensão teórica e político-cultural da multiplicidade da sexualidade, dos gêneros e dos corpos. Isso demanda um rigoroso trabalho de aprofundamento teórico-conceitual e metodológico sobre o tema gênero e diversidade sexual, já que somente pelo estudo é possível que os professores se apropriem da fundamentação científica necessária à adequada abordagem do tema, sem, contudo, negligenciar a necessária sensibilização desses sujeitos para desenvolver o debate, sob pena de despi-la de suas dimensões afetiva e cultural.

\section{REFERÊNCIAS}

BRASIL. Instituto Federal Farroupilha. Projeto Pedagógico do Curso Superior em Licenciatura em Ciências Biológicas, 2015. Disponível em:< http://www.iffarroupilha.edu.br/projeto-pedag\%C3\%B3gico-de-curso/>. Acesso em abr/2018.

LACORTE, K; HAMES, C. Diversidade de Gênero e Sexualidade: um olhar para livros didáticos do ensino fundamental. In: BRANCHER, V. R.; MEDEIROS, B. A.;

MACHADO, F C. Caminhos Possíveis à Inclusão I: Educação, gênero e ações afirmativas; dilemas do nosso tempo. Curitiba: Appris editora, 2018.

LOURO, G. L. Pedagogias da Sexualidade. In: O Corpo Educado: pedagogias da sexualidade. Belo Horizonte, Autêntica, 2001.

LOURO, G. L. Um corpo estranho: ensaios sobre sexualidade e teoria queer. Belo Horizonte: Autêntica, 2004.

LOURO, G. L. Gênero, sexualidade e educação: uma perspectiva pós-estruturalista. 16ª ed. Petrópolis: Vozes, 2014.

MADUREIRA, A. F. do A. Gênero, Sexualidade e Diversidade na Escola: A Construção de uma Cultura Democrática. 2007. 429 f. Tese (Doutorado) - Curso de Psicologia, Instituto de Psicologia, Universidade de Brasília, Brasília, 2007. 
ORGANIZAÇÃO DAS NAÇÕES UNIDAS. Brasil é um dos países que registram mais agressões contra pessoas LGBTI. Disponível em: https://nacoesunidas.org/brasil-e-umdos-paises-que-registram-mais-agressoes-contra-pessoas-lgbti/amp/. Acesso em $25 \mathrm{de}$ abr. de 2019.

SEFFNER, F.; SILVA, R. A. A norma é para cumprir ou para transgredir? O complicado equilíbrio das questões de gênero e sexualidade no ambiente escolar. In: CAREGNATO, C. E.; BOMBASSARO, L. C. Diversidade Cultural: Viver diferenças e enfrentar desigualdades na educação. Porto Alegre, Novello \& Carbonelli, 2013a. p. 61-82.

SEFFNER, F.; SILVA, R. A. Cenas, Intervenção nas Cenas e Encenação: malabarismos na educação em gênero e sexualidade nas escolas. In: CAREGNATO, C. E.;

BOMBASSARO, L. C. Diversidade Cultural: Viver diferenças e enfrentar desigualdades na educação. Porto Alegre, Novello \& Carbonelli, 2013b. p. 203-206.

SEFFNER, F. Um bocado de sexo, pouco giz, quase nada de apagador e muitas provas: cenas escolares envolvendo questões de gênero e sexualidade. Revista Estudos Feministas, Florianópolis, v. 19, n. 2, p.561-588, mai-ago, 2011.

SILVA, E. Corpo e sexualidade: experiências em salas de aula de ciências. In:

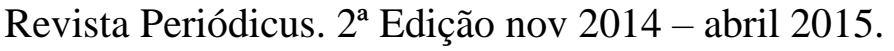

WEEKS, J. O corpo e a sexualidade. In: O Corpo Educado: pedagogias da sexualidade. Belo Horizonte, Autêntica, 2001. p. 35-82. 